\title{
O064. Antiepileptic drugs in migraine and epilepsy disorders: who is at increased risk of adverse events?
}

\author{
Michele Romoli ${ }^{1 *}$, Sabrina Siliquini ${ }^{1}$, Ilenia Corbelli ${ }^{1}$, Stefano Caproni ${ }^{1}$, Chiara Bedetti ${ }^{1}$, Laura Bernetti ${ }^{1}$, \\ Elona Brahimi ${ }^{1}$, Cinzia Costa ${ }^{1}$, Paola Sarchielli ${ }^{1}$, Paolo Calabresi ${ }^{1,2}$ \\ From Abstracts from the 1st Joint ANIRCEF-SISC Congress \\ Rome, Italy. 29-31 October 2015
}

\section{Background}

Migraine and epilepsy are chronic disorders, often comorbid, characterized by transient and recurrent neurological disturbances. Sharing pathophysiologic and clinical features, both epilepsy and migraine benefit from antiepileptic drugs (AEDs) treatment. However, despite their overlapping, peculiar differences regarding reported adverse events (AEs) of AEDs seem to emerge in clinical practice. In particular, tolerability and frequency of AEs might depend on the condition from which the patient suffers. Therefore, we interviewed patients treated with AEDs for epilepsy, migraine, and both, in order to compare AEs distribution of frequency among the three groups.

\section{Materials and methods}

We collected AEs of some AEDs - valproic acid (VPA), topiramate (TPM), lamotrigine (LTG) - widely used in prophylactic therapy of migraine, in epilepsy as well as in epileptic migraineurs. All AEs were gathered through the Liverpool Adverse Events Profile (LAEP) [1].

\section{Results}

Three hundred and thirty-five patients were recruited: 142 suffered from epilepsy (group A), 131 from headache (group B), 62 from both (group C). Mean age was 44.5 in group A, 45.0 in B, 40.5 in C. AEs were significantly more reported in group B (69.5\%) and under TPM treatment (71\%). The most prescribed AED for group B was TPM, which was more commonly referred to cause paresthesias (68\%) and language disorders
(42\%) among this group than in the other two. Complaints of weight gain were common with VPA in all three groups, with higher frequencies among group $\mathrm{B}$ and $\mathrm{C}$. Memory impairment induced by AEDs was reported more frequently for TPM in all three groups, while maximal incidence was reported for VPA and TPM, respectively in group B (5\%) and C (9\%). Overall, migraineurs were more likely to drop out of treatment (46\%) than epileptic patients (29.6\%) and patients with epilepsy and migraine (41.9\%).

\section{Discussion and conclusions}

Our data confirm the extensive safety and effectiveness of AEDs in clinical practice, and point to patient's tolerability of AEs as pivotal for a successful treatment [2]. We emphasize the higher prevalence of AEs due to AEDs in migraineurs, suggesting a peculiar susceptibility of their condition to experience AEs. This finding, which emerges despite the average higher dosage of AED used for epilepsy, remains actually unexplained. Our results might be intriguingly considered as a clinical implication of central sensitization mechanisms or, not less intriguingly, they might represent the result of an abnormal network plasticity producing microstructural changes in migraine-affected brain [3].

Written informed consent to publication was obtained from the patient(s).

\section{Authors' details \\ ${ }^{1}$ Neurology Clinic, Perugia University Hospital, Perugia, Italy. ${ }^{2}$ RCCS Fondazione "S. Lucia", Rome, Italy.}

\footnotetext{
* Correspondence: romoli.mic@gmail.com

${ }^{1}$ Neurology Clinic, Perugia University Hospital, Perugia, Italy

Full list of author information is available at the end of the article
} 


\section{References}

1. Panelli RJ, Kilpatrick C, Moore SM, Matkovic Z, D'Souza WJ, O'Brien TJ: The Liverpool Adverse Events Profile: relation to AED use and mood. Epilepsia 2007, 48(3):456-63.

2. Cramer JA: Tolerability of anti-epileptic drugs: can we determine differences? Epilepsy Behav 2012, 23:187-192.

3. Coppola G, Di Renzo A, Tinelli E, lacovelli E, Lepre C, Di Lorenzo C, Di Lorenzo G, Di Lenola D, Parisi V, Serrao M, Pauri F, Fiermonte G, Bianco F, Pierelli F: Evidence for brain morphometric changes during the migraine cycle: A magnetic resonance-based morphometry study. Cephalalgia 2014, 0(0):1-9, 0333102414559732

doi:10.1186/1129-2377-16-S1-A69

Cite this article as: Romoli et al:: 0064. Antiepileptic drugs in migraine and epilepsy disorders: who is at increased risk of adverse events? The Journal of Headache and Pain 2015 16(Suppl 1):A69.

\section{Submit your manuscript to a SpringerOpen ${ }^{\mathcal{O}}$ journal and benefit from:}

- Convenient online submission

- Rigorous peer review

- Immediate publication on acceptance

- Open access: articles freely available online

- High visibility within the field

- Retaining the copyright to your article

Submit your next manuscript at $\gg$ springeropen.com 